Send your letters to the Editor,

British Dental Journal,

64 Wimpole Street

London

W1G 8YS

Email bdj@bda.org

Priority will be given to letters less than 500 words long.

Authors must sign the letter, which

may be edited for reasons of space.

\section{SAFETY MEASURES}

Sir, with regard to the letter by J. Dhanda et al. about high speed laceration (BDJ 2008; 204: 352) I would like to draw readers' attention to a new device called 'Isolite' which delivers continuous illumination, retraction and isolation (www.isolitesystem.com). It has a unique mouth piece which will retract and protect the cheek and tongue from accidental damage from the high speed turbines. The mouth piece is disposable and hence there is no risk of cross infection, it is easy to place and comfortable for the patient.

V. Ballal, Manipal

DOI: $10.1038 /$ sj.bdj.2008.986

\section{LATEX CONCERNS}

Sir, I have a 62-year-old female patient who suffers from latex allergy. She has expressed concern to me about the possibility of latex being part of toothbrushes which she might purchase and use. She commented that several toothbrushes have what may or may not be latex as part of the toothbrush head, the handle or the tongue scraper. Have any other readers come across these concerns and can toothbrush manufacturers reassure us regarding the absence of latex in their brushes?

R. Evans, Kidlington

DOI: $10.1038 /$ sj.bdj.2008.987

\section{SEDATION IN EUROPE}

Sir, we have read with interest two articles published in the $B D J$ by M. C. G. Manley et $a l^{1}$ and by G. McKenna and S. Manton. ${ }^{2}$ The two papers raise some issues which we feel require further explanation. Provision of adequate anxiety control is both a right for the patient and a duty placed on the dentist. We agree about the efficacy and safety of midazolam to perform dental procedures on those who may otherwise require a general anaesthetic. However, also in recent recommendations ${ }^{3}$ intranasal midazolam administration in patients under the age of 12 years or in adult patients if followed by intravenous administration, is classified in the category of 'alternative techniques' and should be limited to the hospital. ${ }^{4}$

We stress the definition of conscious sedation, as accepted by many European dental societies: A technique in which the use of a drug or drugs produces a state of depression of the central nervous system enabling treatment to be carried out, but during which verbal contact with the patient is maintained throughout the period of sedation. The drugs and techniques used to provide conscious sedation for dental treatment should carry a margin of safety wide enough to render loss of consciousness unlikely. The use of sedation is still a limited practice among European dentists: in Italy sedation is provided mainly by anaesthesiologists (94\%); seldom by dentists (6\%). ${ }^{5}$ Education is carried out on a theoretical basis, while practice on the patient is lacking in the majority of the European dental schools. ${ }^{6}$ With this European scenario we think that in outpatient dentistry a more prudent approach is mandatory. Our advice is to use drugs with a better pharmacological profile for conscious sedation, ie diazepam instead of midazolam. ${ }^{7}$

Given these points, it seems odd to be concerned about preoperative fasting in a setting where the loss of consciousness must be avoided. It is our opinion that fasting for conscious dental sedation is not required unless there is a specific indication. Patients should be advised to eat normally on the day of their appointment avoiding alcoholic drinks and large meals. ${ }^{8}$ The absence of evidence to support our current practice is alarming, but is not substantially different from many other areas in medicine.

G. Zanette, E. Facco, G. Manani, Italy

1. Manley M C G, Ransford N J, Lewis D A, Thompson $S A$, Forbes M. Retrospective audit of the efficacy and safety of the combined intranasal/ intravenous midazolam sedation technique for the dental treatment of adults with learning disability. BrDent J 2008; 205: E3.

2. McKenna G, Manton S. Pre-operative fasting for intravenous conscious sedation used in dental treatment: are conclusions based on relative risk management or evidence? Br Dent J 2008; 205: 173-176.

3. Gilchrist F, Cairns A M, Leicht J A. The use of intranasal midazolam in the treatment of paediatric dental patients. Anaesthesia 2007; 62: 1262-1265.

3. Standards for Conscious Sedation in Dentistry: Alternative Techniques. A Report from the Standing Committee on Sedation for Dentistry, 2007.

4. Zanette $\mathrm{G}$, Robb N, Facco E, Zanette L, Manani G. Sedation in dentistry: current sedation practice in Italy. Eur J Anaesthesio/ 2007; 24: 198-200.

5. Robb N. Training for Pain and Anxiety Control in Dental Schools in Europe. Abstracts from 11th International Federation of Dental Anaesthesiology Societies (IFDAS) Congress: International Dental Congress on Modern Pain Control, 4-7 October 2006, Yokohama, Japan. Anesth Prog 2007; 54: 73-74.

6. Manani G, Baldinelli L, Cordioli G, Consolati E et al. Premedication with chlordemethyldiazepam and anxiolytic effect of diazepam in implantology. Anesth Prog 1995: 42: 107-112.

7. Scottish Dental Clinical Effectiveness Programme Conscious Sedation in Dentistry Dental Clinical Guidance. May 2006. Dundee Dental Education Centre. www.scottishdental.org/cep

DOI: $10.1038 /$ sj.bdj.2008.988

\section{RESULTS OF NEGLECT}

Sir, the letter from Dr Barsam, Between two stools (BDJ 2008; 205: 352) is erroneous in one respect.

As Manager of Monitoring at the DPB at the time the figure was found (early 1990s), I was responsible for setting up the system to monitor the capitation scheme. It transpired that the actual figure for supervised neglect was 3\% of dentists on the register, not the "probably less than 0.5\%' as Dr Barsam stated. 
At the time there were (approximately) 16,800 dentists with a contract to work under the GDS regulations on the register in England and Wales (the DPB only dealt with these regions then).

Three percent of this figure is (approximately) 500, 'about whom we had serious concern', the phrase we used to describe this. I do not remember the average number of child patients ( $<18$ years) a dentist would have had on their list but the number of children being neglected must have run well into six figures.

I suspect we are seeing the results of this neglect today.

The figures were reported to the Department of Health at the time. It is self evident the Department didn't do anything about them.

M. H. Rich, Eastbourne DOI: 10.1038/sj.bdj.2008.989

\section{SICKLE CELL TOOTHACHE}

Sir, a 25-year-old African was recently admitted to Mayday Hospital with chronic pyrexia of unknown cause. Medically he had hepatitis C and sickle cell anaemia. Two weeks later, he reported symptoms of dental pain and was referred to the Department of Restorative Dentistry. The pain, continuous and throbbing in nature, originated from the upper left quadrant, occurring spontaneously and often keeping the patient awake at night.

Extra-oral examination revealed nothing of note. Intra-orally, the patient had BPE scores of 1 , oral hygiene was fair and all of the teeth were present and caries free. Only tooth 36 (UL6) was tender to percussion, there was no associated sinus or swelling but an electric pulp tester failed to get a response. The patient was informed that the tooth may have been losing vitality but, given that it was unrestored and had no obvious crack, the patient was unwilling to have any exploratory treatment carried out. He was advised to take a course of non-steroidal anti-inflammatory drugs for pain relief and was booked in for review two weeks later. The patient cancelled his review appointment as his pyrexia had spontaneously resolved and he had been discharged from hospital. One month later he was contacted and informed us that the tooth had recently developed a swelling and that an emergency dentist had drained the infection through the tooth. He was now symptom free and was seeking a dentist to root treat the tooth.

Given that the patient had sickle cell anaemia, it is possible that sickle cells got trapped in the pulp's vascular supply and impeded the blood flow. This would have lead to hypoxia, cell death and ultimately loss of vitality and symptoms of pulpitis. ${ }^{1}$ Without treatment, the inflammatory process could have progressed to the apical tissues and stimulated the development of a dental abscess. Indeed there have been reports of patients with sickle cell disease developing spontaneous symptoms of pulpitis ${ }^{2}$ and requiring treatment. These cases have caused diagnostic puzzles as the teeth themselves were clinically and radiographically sound.

We feel that this is an interesting case report as the patient's symptoms (alongside the absence of any dental disease) would have correlated with a diagnosis of atypical odontalgia. Such patients are typically counselled and prescribed a course of tricyclic antidepressants. This particular case is unusual in that an unrestored tooth clearly required root canal treatment (or even extraction) but the cause of the tooth losing vitality was not dental disease but possibly the patient's underlying haematological disease.

\section{R. Ali, C. Oxlade, E. Borkowska Croydon}

1. Andrews $\mathrm{CH}$, England M C, Kemp W B. Sickle cell anaemia: an aetiological factor in pulpal necrosis. J Endod 1983; 9: 249-252.

2. Bishop K, Briggs P, Kelleher M. Sickle cell disease; a diagnositic dilemma. Int Endod J 1995; 28: 297-302.

DOI: 10.1038/sj.bdj.2008.990

\section{SUPPORT PROGRAMME}

Sir, the recent paper by Kay and Lowe (BDJ 2008; 204: E19) provides an interesting, unique and valuable perspective on our profession's view on stress levels, health and health related behaviours.

The Short Michigan alcohol screening test (SMAST) 'indicated that dentists seemed more likely to have alcoholic tendencies than they were ten years ago'. The results reported that ' $6 \%$ of respondents had a drink problem and 9\% had alcoholic tendencies' which suggests that alcoholic tendencies/alcoholism is rising within the profession.

The alcoholic/addicted dentist can experience many difficulties professionally and personally and, if this disease is left untreated, can suffer PCT and GDC investigation, loss of registration, loss of income, financial worries, bankruptcy, domestic violence, divorce, emotional damage to children, involvement with the police, court appearances, loss of self worth, suicide ... and ... premature death!

Sadly, it is not only the dentist who suffers - spouses, partners and children are also deeply affected with many children continuing to suffer the effect of an uncertain or chaotic childhood into adulthood and throughout their lives. Dentists need to be aware of alcoholism /drug dependency as a primary disease which can be treated with successful outcomes. The alcoholic/drug dependent dentist need not fear treatment as it can return him/her to a fulfilled and productive personal and professional life and provide the means to remake personal and professional relationships.

The British Doctors and Dentists Group (BDDG), founded in 1975, consists of dentists and doctors who are recovering from alcoholism or drug dependency. Groups are scattered around the country and meet regularly to share, in confidence and without judgement, personal, professional and living problems related to their addiction and to support each other in recovery. Details are available, in confidence, from the National Secretary, Dr Paul R on 07771642682 or from www.bddgchelmsford.com.

The Dentists Health Support Programme (DHSP) offers a confidential helpline, guidance and support to dentists who are in difficulty as a result of alcohol or drugs: the DHSP Helpline number is 02072244671.

Support for relatives and friends of dentists who are suffering from alcoholism or drug addiction is offered through The BDDG Family Members Group. Relatives and children of addicted dentists are emotionally damaged as a consequence of the addicted dentist and need their own recovery. The groups provide a safe place to share life experiences, knowledge and hope, in confidence and 
without judgement. Meetings are held around the country with details, in confidence, from Cecile D 01737813921 or www.bddgfamilies.org.uk.

For anyone of our profession who has a problem with alcohol or drugs, The British Doctors and Dentists Group or the Dentists Health Support Programme can help you on the road to recovery from this disease.

H. J. Breen, K. Collins, R. O'Connor

By email

DOI: 10.1038/sj.bdj.2008.991

\section{NOTHING TO SNIFF AT}

Sir, with current smoking patterns about 500 million people alive today will eventually be killed by tobacco use, so that by 2030 tobacco is expected to be the single biggest cause of death worldwide accounting for about 10 million deaths per year. One half of these deaths will occur among people 35 to 69 years of age, losing an average of 20-25 years of life.

The effect of tobacco use on oral health is also alarming. All forms of tobacco have been established as causes for oral and pharyngeal cancer. Smokeless tobacco commonly comes in two basic forms, snuff and chewing tobacco. Snuff is finely ground tobacco packaged in cans or pouches and is of two types, namely dry and moist. Moist snuff is used by placing the pinch, dip, lipper or quid between the lower lip or cheek and gum. Nicotine is absorbed through the tissues of the mouth. Dry snuff is sold in the powdered form and is used by sniffing or inhaling up the nose.

Snuff in both forms is not a safe substitute for tobacco smoking leading to harmful health effects such as oral cancer, alveolar bone loss, pancreatic cancer and leukoplakia.

As well as containing the highly addictive nicotine, snuff also contains very high levels of tobacco specific nitrosamines. Nicotine replacements such as nicotine gums, patches and lozenges provide nicotine without the other harmful ingredients in tobacco and these should be considered when advising patients to quit tobacco use. Dental practice in the twenty-first century will increasingly move towards promotion of health and wellbeing and in terms of snuff, which is often adopted by young people as a lifestyle choice, we should advise our patients to quit.

A. Kaushal, M. Kamboj, Lucknow DOI: 10.1038/sj.bdj.2008.992

\section{A SINGLE DOSE}

Sir, I was interested to read the letter Dry socket secrets (BDJ 2008; 204: 703). I have written in similar vein on two previous occasions in the $B D J$ and last year carried out a short survey of the incident of dry socket. During the period I extracted 263 teeth of which 63 were surgical extractions of varying difficulties including a few challenging lower third molars. I had four cases of 'dry socket' which equates to $1.52 \%$, a similar figure to the $1.45 \%$ recorded by J. A. Speechley. My secret is giving a single dose of $200 \mathrm{mg}$ metronidazole post operatively with the distressing advice that no alcohol can be consumed that day; made worse if it is a Friday!

P. R. Williams, Lowestoft DOI: 10.1038/sj.bdj.2008.993

\section{WIKIPEDIA COMES SECOND}

Sir, I am delighted to see the publication of a series of articles about special care dentistry in the BDJ. However, I was surprised to see that three references in Access to special care dentistry, part 6. Special care dentistry services for young people (BDJ 2008; 205: 235-249) came from Wikipedia. Whilst I accept that information on pica may be difficult to find, and so Wikipedia might have been accessed as a last resort, there is a wealth of information about obsessive-compulsive and bipolar disorders available from more reputable sources.

For example, they are covered by the excellent range of clinical guidelines produced on mental health and behavioural conditions by the National Institute for Health and Clinical Excellence (www.nice.org.uk). Additionally, the 'Overcoming' series of books (www. overcoming.co.uk) is recommended by several local NHS 'Books on Prescription' schemes, and deals with these mental health difficulties.

I would most certainly turn to either of these sources before using Wikipedia.

C. Stillman-Lowe

By email

DOI: $10.1038 /$ sj.bdj.2008.994 